\title{
Utilization of steel plants waste
}

\begin{abstract}
Utilization of waste generated by steel plants has become a crucial issue due to evertightening environment regulations. Such rules implemented on steel makers have raised the circumstances to reduce the wastes generated by steel plants. Approximately $500 \mathrm{~kg}$ waste materials are generated per tonne of crude steel by the steel plant. Additionally, the depletion of high-grade iron ores imposes broad research work to utilize the waste materials. Nowadays, considering all waste materials as an economical asset; there is a focus on zero waste generation by $100 \%$ recycling of waste. How to utilize steel plants' waste in existing processing technology is highly challengeable for steel makers. One of the waste materials, mill scale is having rich content of iron; hence it should be transformed into valuable product i.e. steel. In the present work, an attempt is made to produce nonagglomerated sinter cake of mill scale with different proportions of charcoal fines on the basis of stoichiometric calculations. Different amount of lime is also added to improve the strength of sinter cake. Degree of reduction and compressive strength of the sinter cake were measured. Characterization studies were also carried out by using scanning electron microscopy (SEM) and energy dispersive analytical X-ray (EDAX). A uniform texture of fine metallic particles confirmed that homogeneous reduction has occurred. Best result was achieved in sinter cake containing $10 \%$ excess charcoal of stoichiometry and $20 \%$ lime in which compressive strength obtained is $182 \mathrm{~kg} / \mathrm{sample}$ and degree of reduction $(\alpha)$ is $47.8 \%$. This sinter cake was charged along with Thermo-mechanically treated (TMT) steel scrap to check the feasibility of steel making in induction furnace. The experimental result shows that the waste product can be used successfully for production of steel.
\end{abstract}

Keywords: waste utilization, mill scale, non-agglomerated sinter, steelmaking, domestic steel, crude steel, economic asset
Volume 2 Issue 5 - 2018

\author{
Yakshil Chokshi, ${ }^{1,2}$ Neelam Sompura, ${ }^{2}$ Dutta \\ SK' \\ 'Metallurgical \& Materials Engineering Department, Maharaja \\ Sayajirao University of Baroda, India \\ ${ }^{2}$ Government Polytechnic, Rajkot, India
}

Correspondence: Dutta SK, Former Professor \& Head, Metallurgical \& Materials Engineering Department, Maharaja Sayajirao University of Baroda, India, Email drskduttaI98I@gmail.com

Received: March 31, 2018 | Published: September 25, 2018

\section{Introduction}

World produced 1,689 million tonne (Mt) of crude steel in 2017, is increased about $3.8 \%$ production with respect to 2016 (1627 Mt). India is a third largest producer of steel in the world which is preceded by China and Japan. Iron and steel industry's growth in India has been exceptional since last 10 years. India's crude steel production of year 2017 is $101.4 \mathrm{Mt}$ which was $53.5 \mathrm{Mt}$ in year of 2007. Correspondingly, the per capita steel consumption in the country was $43 \mathrm{~kg}$ in the year of 2007 which increased to $65 \mathrm{~kg}$ in the year of $2017 .{ }^{1}$ As per National steel policy 2017 (NSP), estimated domestic steel production of 300Mt will be achieved by 2030-31. Reaching out to this visionary aim, Indian steel plants must have to discontinue outdated technologies, increase their production capacities, uplift the efficiency of operations, implement latest technologies, utilize low-grade raw materials as well as minimize waste generation. Considering all waste materials as an economic asset, Ministry of Steel, Government of India ${ }^{2}$ will encourage the steel companies to develop a Waste Management Plan for additional impetus on zero-waste or complete waste recycling.

In several iron and steel making processes, ${ }^{3}$ about $500 \mathrm{~kg} / \mathrm{t}$ of solid wastes of different nature are generated. Das et al., ${ }^{4}$ have been reviewed and briefly reported on utilization of steel plant wastes in the several industries. The various solid wastes in the form of slags and sludges that are emerged from steel plants are blast furnace slag, blast furnace flue dust and sludge, Linz-Donawitz (LD) converter slag, LD sludge, LD dust, mill scale, mill sludge, acetylene sludge, etc. The solids and liquid wastes generated from a steel plant are shown in Table 1 . The composition of these materials vary widely depending on the source of generation but usually contains some useful resources such as iron, carbon, calcium, zinc, lead, etc., which can be recovered and reused in a judicious manner.

Table I Types of solid/liquid waste generated from steel plants ${ }^{4}$

\begin{tabular}{lll}
\hline $\begin{array}{l}\text { Solid/liquid } \\
\text { wastes }\end{array}$ & Amount $\mathbf{( k g / t )}$ & Source of generation \\
\hline Coke breeze & - & Coke oven \\
Nut coke & - & Coke oven \\
Coke dust/sludge & - & Coke oven \\
Blast furnace slag & $340-42 \mathrm{I}$ & Blast furnace \\
$\begin{array}{l}\text { Blast furnace dust/ } \\
\text { sludge }\end{array}$ & 28 & Blast furnace \\
Sintering plant & - & Sintering plant \\
LD slag & 200 & Steel melting shop \\
LD sludge & $15-16$ & Steel melting shop \\
Lime fines & - & Steel melting shop \\
ACP/GCP sludge & - & Steel melting shop \\
Carbide sludge & - & Acetylene plant \\
Mill scale & 22 & Mills \\
Mill sludge & 12 & Rolling mills \\
Refractory, bricks & $1 \mathrm{I} .6$ & Steel melting shop /mills, \\
Sludges/scales & - & etc. \\
Fly ash & - & Water treatment plant \\
\hline
\end{tabular}

During deformation of steel to long or flat product, mill scale is 
formed; when steel is subjected to expose at high temperature oxidation atmospheres, which promotes the growth of iron oxides layer at the surface of steel. The generation of mill scale represents about $2 \%$ of steel produced (approximately 1.9Mt in 2016 year) and is available as a secondary material due to its richness in iron (about $72 \%$ total $\mathrm{Fe}) .^{5}$ Since, it is composed of various oxides of iron primarily $\mathrm{Fe}_{3} \mathrm{O}_{4} ; \mathrm{Fe}_{2} \mathrm{O}_{3}$ and $\mathrm{FeO}$ are also present in small quantities. Mill scale is bluish black in colour and is usually less than one mm thick. Until last decade, solid wastes produced by integrated steel plants were called waste, but now this term is replaced as by-product due to intrinsic utilization of these wastes. ${ }^{6}$ It is possible to use this mill scale for pure iron powder production.

In India, $90 \%$ structural steels are produced by secondary sector where used mostly induction furnaces. Mill scale is rejected as a waste which would be recycled for recovery of metallic iron. There is lack of facilities for recycling of mill scale at the smaller capacity plants; due to absence of a sinter making facility in such units does not offer any scope for in-house recycling of mill scale. ${ }^{5}$

Research works ${ }^{5-10}$ have been carried out on various processes for use of mill scale as a charge material for iron and steel making. Due to fine size of mill scale, it is being agglomerated with or without carbonaceous material either by briquetting or sinter making. Further, reduction was done by reducing materials (e.g. coal/charcoal/coke fines, $\mathrm{CO}$ or $\mathrm{H}_{2}$ gas). Isothermal carbothermic reduction process shows potential to efficiently utilize mill scale as an agglomerated charge material. ${ }^{10}$ Mill scale and carbonaceous material such as coal or charcoal were processed in blended powder form at different temperatures $(1073 \mathrm{~K}, 1173 \mathrm{~K}, 1273 \mathrm{~K}$ etc.) for different holding time (15-120 min). Different amounts of coals were used, and the particle size of raw materials was also varied. The result showed that rate of reduction increased with time and temperature but decreased with increasing of particle size. Further, addition of flux can also be increased the rate of reaction.

In the present work, an attempt is made to produce nonagglomerated sinter cake of mill scale with coal fines. Further study is on feasibility of steelmaking by charging with different proportions of sinter cake and steel scrap in induction furnace.

\section{Experimental work}

\section{Chemical analysis}

Mill scale and scrap of TMT rods were procured from M/s. Punjab TMT Rolling Mill Ltd., Vadodara, India. Charcoal was procured from local market. Chemical analyses of mill scale are carried out by wet volumetric method as well as bulk chemical analysis by using energy dispersive X-ray fluorescence analysis (EDXRF) 800 Shimadzu, Japan. The chemical analyses of mill scale are illustrated in Table 2. Proximate analysis of as received charcoal powder sample is carried out by ASTM D3172 standard method. Table 3 The chemical composition of the TMT bar scrap employed in this work is given in Table 4.

Table 2 Chemical analysis of mill scale

\begin{tabular}{lllllllll} 
Analyte & $\mathbf{F e}_{\mathbf{t}}$ & $\mathbf{S i}$ & $\mathbf{M n}$ & $\mathbf{C r}$ & $\mathbf{C u}$ & $\mathbf{A l}$ & $\mathbf{P}$ & $\mathbf{O}$ \\
\hline wt.\% & 69.82 & 0.52 & 0.43 & 0.21 & 0.16 & 0.19 & 0.01 & Balanced
\end{tabular}

Table 3 Proximate analysis of charcoal

\begin{tabular}{llllll}
\hline Analyte & Moisture & $\begin{array}{l}\text { Volatile } \\
\text { Matter }\end{array}$ & Ash & $\begin{array}{l}\text { Fixed } \\
\text { carbon }\end{array}$ & Total \\
\hline wt.\% & 6.55 & 19.9 & 5.5 & 68.05 & 100.0 \\
\hline
\end{tabular}

Table 4 Chemical analysis of scrap of TMT rods

\begin{tabular}{lllllllllll}
\hline Analyte & $\mathbf{F e}_{\mathbf{t}}$ & $\mathbf{C}$ & $\mathbf{M n}$ & $\mathbf{S}$ & $\mathbf{P}$ & $\mathbf{C r}$ & $\mathbf{A l}$ & $\mathbf{C u}$ & $\mathbf{S i}$ & Total \\
\hline wt.\% & 98.33 & 0.19 & 0.79 & 0.02 & 0.04 & 0.16 & 0.16 & 0.09 & 0.22 & 100.0 \\
\hline
\end{tabular}

\section{Sinter making and reduction studies}

Mill scale and charcoal powder were sintered in non-agglomerate condition. Mill scale was placed at the center of the metal mould and surrounded by charcoal. Lime was used as slag bonding in between of particles. Sintering operation was carried out in a laboratory scale electrically heated muffle furnace. For reduction studies, temperature and time was $1223 \mathrm{~K}$ and 60 minutes respectively. Quantity of charcoal and lime was varied for the non-agglomerated sinter cake production. Compressive strength and degree of reduction of sinter cakes were measured.

Wang et al., ${ }^{11}$ developed equation to calculate the degree of reduction $(\alpha)$ of iron ore-coal composite pellets as follows:

$$
\alpha=\left[\left(\frac{4}{7 m_{0}}\right) \times\left\{\Delta m_{t}-\left(m x f_{v}\right)\right\}\right] \times 100
$$

Now this Eq. (1) is modified by Sah \& Dutta ${ }^{12}$ as follows:

$$
\alpha=\frac{400}{7} \times \frac{\left[\Delta \mathrm{m}_{\mathrm{t}}-\left(\mathrm{m} \times \mathrm{f}_{\text {coal }} \times \mathrm{f}_{\mathrm{vm}}\right)\right]}{\left(\mathrm{m} \times \mathrm{f}_{\text {ore }} \times \mathrm{f}_{\mathrm{o}} \times \rho_{\text {ore }}\right)}
$$

Where, $\Delta m_{t}=$ Total weight loss, gm $m=$ Initial weight, gm

$f_{\text {coal }}=$ Fraction of coal,

$\mathrm{m}_{0}=$ Total removable oxygen present in iron oxide, gm

$\mathrm{f}_{\mathrm{v}}=$ factor of devolatilization

$f_{v m}=$ Fraction of volatile matter,

$f_{\text {ore }}=$ Fraction of ore,

$f_{o}=$ Fraction of oxygen and

$\rho_{\text {ore }}=$ Purity of ore.

\section{Melting practice}

Melting was done in laboratory scale induction furnace $(6 \mathrm{~kg}$ capacity). TMT rods (as a scrap) and non-agglomerated sinter cake were charged with different proportion. Initially TMT rods are melted in induction furnace to make molten bath. Sinter cake was slowly charged and that was dissolved in molten bath. Lime was also added as a fluxing agent. After proper attending temperature of the bath, molten metal was poured into the sand mould. After proper cooling, casted sample was taken out from the mould and was chemically analyzed (as shown in Table 5) by Optical Emission Spectroscopy (OES). 


\section{Characterization and microstructure studies}

The raw materials have been characterized by volumetric chemical analysis, X-ray fluorescence (XRF), scanning electron microscopy (SEM) and energy dispersive analytical X-ray (EDAX). A Jeol SEM (Model: JSM-5610 LV), which is coupled with Oxford EDAX system, is used to characterize the morphology of sinter cake.

Table 5 Chemical analysis of produced steels

\begin{tabular}{lllllll}
\hline Analtye (wt.\%) & C & Si & Mn & P & S & Fe \\
\hline Heat I (90:10) & 0.22 & 0.52 & 0.27 & 0.03 & 0.03 & 98.93 \\
Heat 2 (85:15) & 0.27 & 0.59 & 0.35 & 0.03 & 0.04 & 98.72 \\
Heat 3 (80:20) & 0.29 & 0.68 & 0.16 & 0.04 & 0.03 & 98.80 \\
\hline
\end{tabular}

\section{Result and discussion}

\section{Compressive strength and reduction studies}

Figure 1 shows the produced non-agglomerated sinter cake. Table 6 shows the results of compressive strength and degree of reduction $(\alpha)$ of sinter cakes. Higher percentage of charcoal and/or lime was shown good results of non-agglomerated sinter. Best combination of degree of reduction and compressive strength were obtained in $10 \%$ excess charcoal of stoichiometry and $20 \%$ lime. Highest compressive strength was achieved in sinter cake of $10 \%$ excess charcoal of stoichiometry and $30 \%$ lime. Overall, addition of lime is favorable to the strength as well as degree of reduction of sinter which are required for steel making.

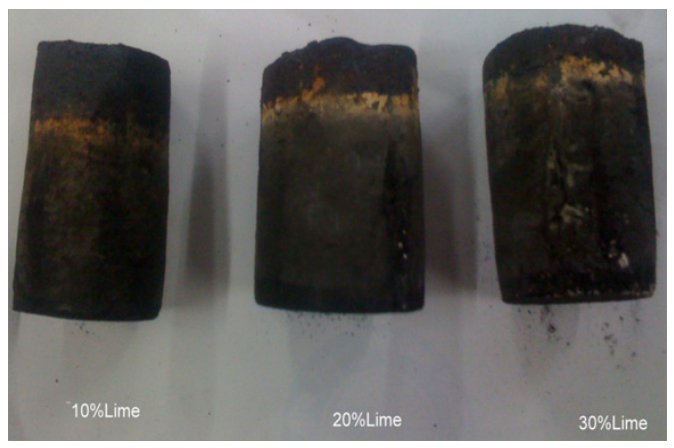

Figure I Non-agglomerated sinter cake.

Table 6 Resultant properties of non-agglomerated sinter

\begin{tabular}{lll}
\hline Charcoal as ‘Carbon' (wt. \%) & $\begin{array}{l}\text { Compressive } \\
\text { strength (kg/ } \\
\text { sample) }\end{array}$ & $\begin{array}{l}\text { Degree of } \\
\text { reduction } \\
(\%)\end{array}$ \\
\hline$<05 \%$ of stoichiometric & 129 & 5.56 \\
$<10 \%$ of stoichiometric & 108 & 9.65 \\
Stoichiometric & 166 & 10.81 \\
$>05 \%$ of stoichiometric & 133 & 15.28 \\
$>10 \%$ of stoichiometric & 142 & 20.31 \\
$>10 \%$ of Stoichiometric $+10 \%$ lime & 178 & 32.19 \\
$>10 \%$ of Stoichiometric $+20 \%$ lime & 182 & 47.84 \\
$>10 \%$ of Stoichiometric $+30 \%$ lime & 195 & 43.30 \\
\hline
\end{tabular}

\section{Characterization and microstructure observation}

Sinter cake was characterized by SEM-EDS. SEM image shows rough morphology of sinter (as shown in Figure 2). Fine precipitated particles and reduced metallic particles were observed at rough surface. Total $\mathrm{Fe}$ characterized is about $81 \%$ which confirmed that the reduction mechanism has taken place and reduced metallic $\mathrm{Fe}$ is present. Uniform texture of fine metallic particles was confirmed the homogeneous reduction mechanism.

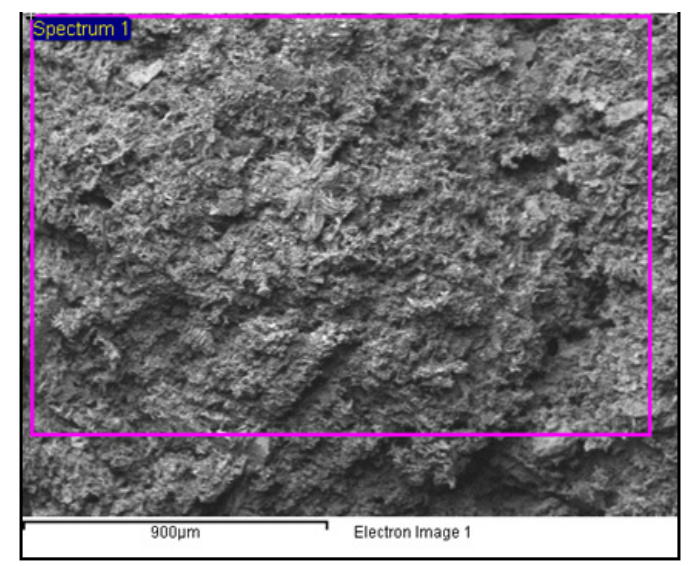

Figure 2 SEM image of non-agglomerated sinter cake.

Annealed steel sample was examined under microscope for microstructure observation. Texture of microstructure confirmed the hypoeutectic type of steel. Phases of ferrite and pearlite were clearly observed (Figure 3).

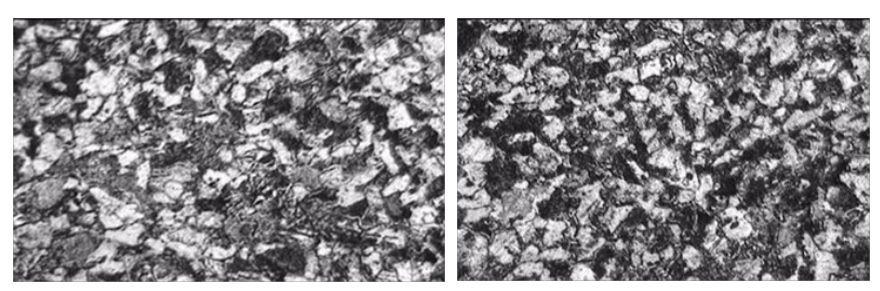

Figure 3 Microstructure of annealed steel at 200X.

\section{Conclusion}

Utilization of mill scale, one of the steel plant wastes has shown better prospect in terms of high recovery of iron by non-agglomeration technique in the unorganized steel sector (majorly Induction Furnace route). This research work produced a non-agglomerated sinter cake from the steel plant waste (i.e. mill scale) that can be used in manufacture of steel.

Based on this research work, following conclusion have been made:

a) Non-agglomerated sinter making process helps to nullify the energy consumption by the agglomeration operation.

b) Best degree of reduction $(\alpha=47.84 \%)$ value was obtained in sinter cake of $10 \%$ excess stoichiometric charcoal and $20 \%$ lime.

c) Best compressive strength $(195 \mathrm{~kg} / \mathrm{sample})$ was achieved in sinter cake of $10 \%$ excess stoichiometric charcoal and $30 \%$ lime.

d) Lime imparted binding strength to the sinter and acted as a fluxing agent in steel making as well.

e) SEM-EDAX analyses confirmed that uniform reduction and metallization has taken place. 
f) 10 to $20 \mathrm{wt}$ \% of sinter cakes were charged as a raw material along with TMT scrap to produce steel successfully.

g) There is an increase in the amount of slag produced with the increase in the amount of sinter cake charged, that due to lime content.

h) The impurity compounds present in the sinter cake will not impose any detrimental effect on the properties of steel produced.

\section{Acknowledgements}

None.

\section{Conflict of interest}

Authors declares that there is no conflict of interest.

\section{References}

1. World steel in figures 2018. World Steel Association.

2. National Steel Policy 2017. Ministry of Steel (Establishment Division), Notification, New Delhi, India. 2017;8:1-36.

3. Bagatini MC, Zymla V, Osório E, et al. Characterization and Reduction Behavior of Mill Scale. ISIJ International. 2011;51(7):1072-1079.
4. Das B, Prakash S, Reddy PSR, et al. An overview of utilization of slag and sludge from steel industries. Resources, Conservation and Recycling. 2007;50(1):40-57.

5. Paswan D, Malathi M, Minj RK, et al. Mill Scale: A Potential Raw Material for Iron and Steel Making. Steelworld. 2015;21:54-56.

6. Gade N, Verma G, Sen R, et al. Effect of Calcium Carbonate on the Reduction Behaviour of Mill Scale. Procedia Earth and Planetary Science. 2015;11:319-324.

7. Eissa M, Ahmed A, El-Fawkhry M, et al. Conversion of Mill Scale Waste into Valuable Products via Carbothermic Reduction. Journal of Metallurgy. 2015;2015:9.

8. Benchiheub O, Mechachti S, Serrai S, et al. Elaboration of iron powder from mill scale. J Mater Environ Sci. 2010;1(4):267-276.

9. Gaballah NM, Zikry AF, Khalifa MG, et al. Production of Iron from Mill Scale Industrial Waste via Hydrogen. Open Journal of Inorganic Non-Metallic Materials. 2013;3(3):23-28.

10. Mistri M, Bhatt A. B.E. Thesis. Met \& Mates Engg Dept. MSU Baroda; 2011.

11. Wang Q, Yang Z, Tian J, et al. Reduction kinetics of iron ore-coal pellet during fast heating. Ironmaking Steelmaking. 1998;25:443-447.

12. Sah R, Dutta SK. Kinetic Studies of Iron Ore-Coal Composite Pellet Reduction by TG-DTA. Trans Indian Inst Met. 2012,64(6):583-591. 